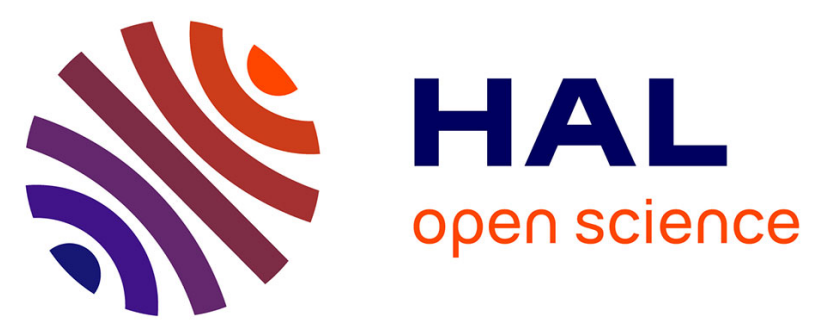

\title{
A New Direct Magnetic Method for Determining Jc in Bulk Superconductors from Magnetic Field Diffusion Measurements
}

Bruno Douine, Frédéric Sirois, Jean Lévêque, Kévin Berger, Charles-Henri Bonnard, The-Cuong Hoang, Smail Mezani

\section{To cite this version:}

Bruno Douine, Frédéric Sirois, Jean Lévêque, Kévin Berger, Charles-Henri Bonnard, et al.. A New Direct Magnetic Method for Determining Jc in Bulk Superconductors from Magnetic Field Diffusion Measurements. IEEE Transactions on Applied Superconductivity, 2012, 22 (3), pp.9001604. 10.1109/TASC.2011.2179409 . hal-00627073v3

\section{HAL Id: hal-00627073 \\ https://hal.science/hal-00627073v3}

Submitted on 27 Apr 2012

HAL is a multi-disciplinary open access archive for the deposit and dissemination of scientific research documents, whether they are published or not. The documents may come from teaching and research institutions in France or abroad, or from public or private research centers.
L'archive ouverte pluridisciplinaire HAL, est destinée au dépôt et à la diffusion de documents scientifiques de niveau recherche, publiés ou non, émanant des établissements d'enseignement et de recherche français ou étrangers, des laboratoires publics ou privés. 


\title{
A New Direct Magnetic Method for Determining $\mathrm{J}_{\mathrm{C}}$ in Bulk Superconductors from Magnetic Field Diffusion Measurements
}

\author{
Bruno Douine, Frédéric Sirois, Senior member IEEE, Jean Leveque, Kevin Berger, Charles-Henri \\ Bonnard, The-Cuong Hoang and Smaïl Mezani
}

\begin{abstract}
The knowing the critical current density $J_{C}$ is important to calculate AC losses in superconducting applications. Usually $J_{C}$ can be obtained from magnetization measurements or electric measurements based on global quantities as the magnetic flux or the voltage. In this paper a quick and direct magnetic method for determining $J_{C}$ is proposed. It is based on direct measurements of local magnetic field in the gap between two bulk HTS pellets. Field penetration measurements were carried out on HTS pellets at $77 \mathrm{~K}$ by applying increasing axial magnetic fields with a quasi constant sweep rate. This determination of $J_{C}$ is theoretically based on Bean model. $J_{C}$ is deduced from the complete penetration magnetic field $B_{P} . B_{P}$ is deduced from the delay $T_{P}$ between the applied magnetic field $B_{a}(t)$ and the magnetic field at the center between the two pellets $B_{0}(t)$. Numerical calculations allow deducing $J_{C}$ more precisely from theoretical calculations and measurements. The numerical calculations are made with the power law $E=E_{C}\left(J / J_{C}\right)^{n}$. For the determination of $J_{C}$ the influence of the gap due to Hall probe sensor and the applied magnetic field rise rate are taken into account. The influence of thermal is also studied.
\end{abstract}

Index Terms - Superconductor, magnetic field diffusion, critical current density

\section{INTRODUCTION}

$\mathrm{T}^{\mathrm{k}}$ he value of $J_{C}$ can be derived from different experimental techniques as transport current, magnetization cycle [1], [2] or ac susceptibility [3]. The electrical transport method is not valid in the case of pellet because this method practically only works for wire. Magnetic methods are called indirect method because relation between measurement and $J_{C}$ is not direct. Magnetization methods need complex and expensive devices as Physical Properties Measurement System or other set up [1], [2]. For AC susceptibility method the relation between measure and $J_{C}$ is complicated because it needs calculation of demagnetizing factor, integration and so on [3], [4].

The main contribution of the present work is to propose a

B. Douine, J. Lévêque K. Berger, C.H. Bonnard, T.Hoang and S. Mezani are with the Nancy University, Groupe de Recherche en Electrotechnique et Electronique de Nancy, 54506 Vandoeuvre, France (e-mail: bruno.douine@green.uhp-nancy.fr,_jean.leveque@green.uhp-nancy.fr, kevin.berger@green.uhp-nancy.fr, smail.mezani@green.uhp-nancy.fr).

F. Sirois is with Ecole Polytechnique of Montreal, Montreal, QC H3C3A7, Canada (e-mail : f.sirois@polymtl.ca) new direct magnetic $J_{C}$ determination method. In this method HTS sample is submitted to an axial applied magnetic field $B_{a}(t)$ (Fig. 1). $B_{a}(t)$ is considered as linear function of times even if the shape of $B_{a}(t)$ does not matter with Bean model:

$$
B_{a}(t)=V_{b} . t
$$

At the center of the pellet the magnetic field begins to increase with delay time $\mathrm{T}_{\mathrm{P}}$ when $B_{a}$ reaches the complete magnetic field $B_{P}$ (Fig. 2). For short cylinders and with the Bean model [5], an explicit expression of the penetration magnetic field $B_{P}$ can be calculated as the axial magnetic field created in the center of solenoid of null internal radius [6]:

$$
B_{P}=\frac{\mu_{0} J_{C} \cdot L}{4} \cdot \ln \left(\frac{\sqrt{R^{2}+\left(\frac{L}{2}\right)^{2}}+R}{\sqrt{R^{2}+\left(\frac{L}{2}\right)^{2}}-R}\right)
$$

$L$ is the length of the cylinder and $R$ its radius.

(2) is equivalent of $B_{p}$ formula given by different authors [2], [7], [8].

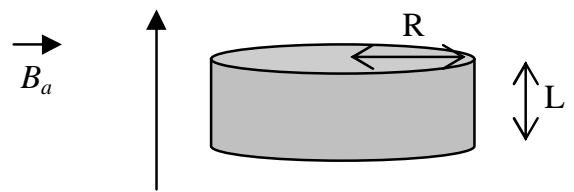

Fig. 1. A cylindrical superconducting sample with axis parallel to the applied magnetic field

The principle of this method is measuring $B_{P}$ and deducing $J_{C}$. In this paper, firstly, experimental results are presented and discussed. Secondly, computational method is exposed. Thirdly numerical simulations with COMSOL Multiphysic 4.1 software allow studying the influence of Hall probe depth and rise rate.

\section{EXPERIMENTAL SETUP AND RESULTS}

Some authors already used Hall probes to determine magnetic field distribution in superconducting sample [9][13]. In our method the complete penetration magnetic field 
is detected with an axial Hall probe placed between two HTS pellets (Fig. 3) at the center of pellet. At this point the magnetic field has only axial component so magnetic field is well measured with this Hall probe. These two pellets are theoretically considered as one pellet. So in a first time the influence of the Hall probe thickness $e$ is neglected. Discussion about this hypothesis will be done in section IV.

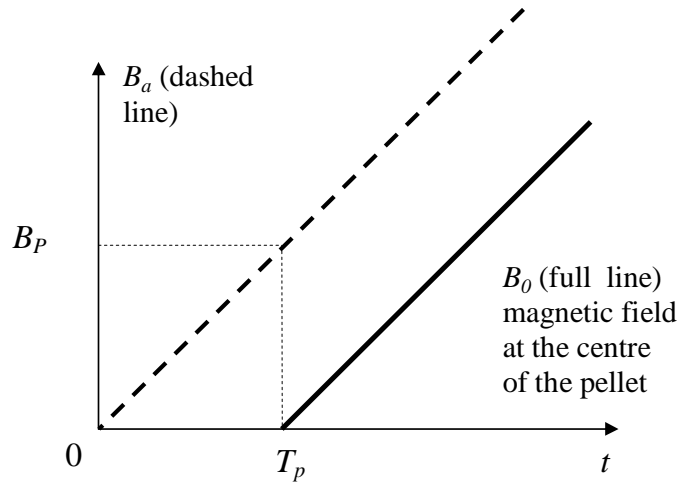

Fig. 2. Linear magnetic applied field $B_{a}$ and theoretical magnetic field at the center of the pellet $B_{O}$ versus time

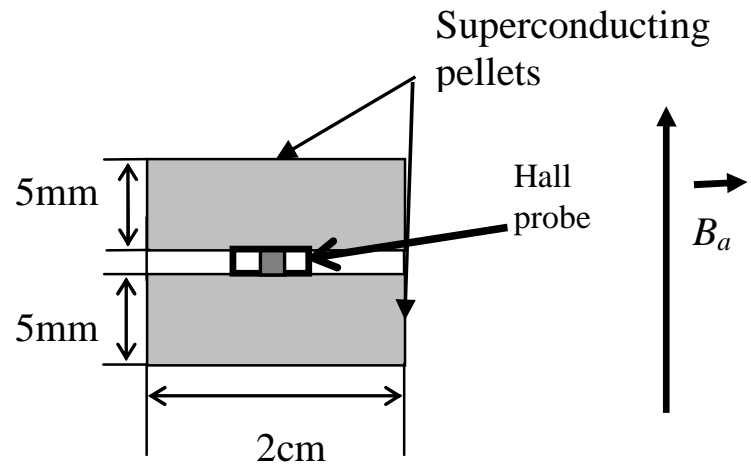

Fig. 3. Hall probe location and HTS pellet dimensions

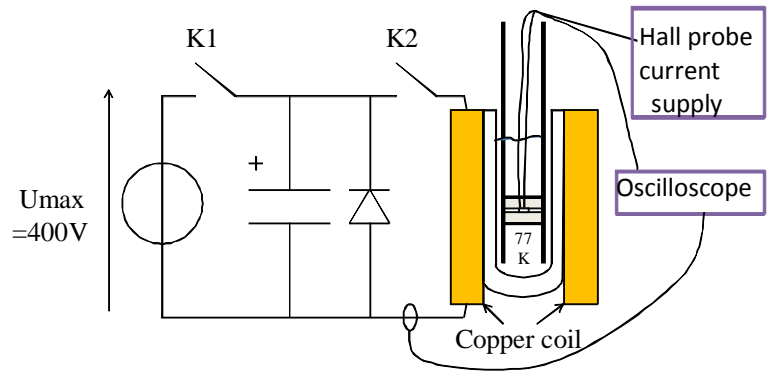

Fig. 4. Experimental set up

Fig. 4 shows our experiment with the pulsed field magnetization process [14] that is used to apply magnetic field with a copper coil. A previously charged capacitor is discharged through this copper coil. It allows obtaining quasi constant rise rate $V_{b}$ equals to $660 \mathrm{~T} / \mathrm{s}$. With this process there is no need of superconducting coil in order to obtain high magnetic field of several Tesla. The applied magnetic field $B_{a}(t)$ is deduced from copper coil current and the magnetic field at the center of the two pellets $B_{0}(t)$ is measured with Hall probe. Figure 5 shows the experimental results. As you can see in surrounded part of Figure 5, the beginning of $B_{0}(t)$ has not exactly the same shape as the beginning of $B_{a}(t)$. As it will be confirmed in section IV, this is due to the necessary space between pellets to place Hall probe. So the determination of the penetration time $T_{P}$ is done as follow. The measured magnetic field curve at the pellet center is modified around $T_{P}$ to be a copy of applied magnetic field $B_{a}(t)$ (dotted line in Fig. 5). All along time the difference between curves is constant and equal to $T_{P}$. $T_{P}$ determined then $B_{P}$ is deduced from the curves.

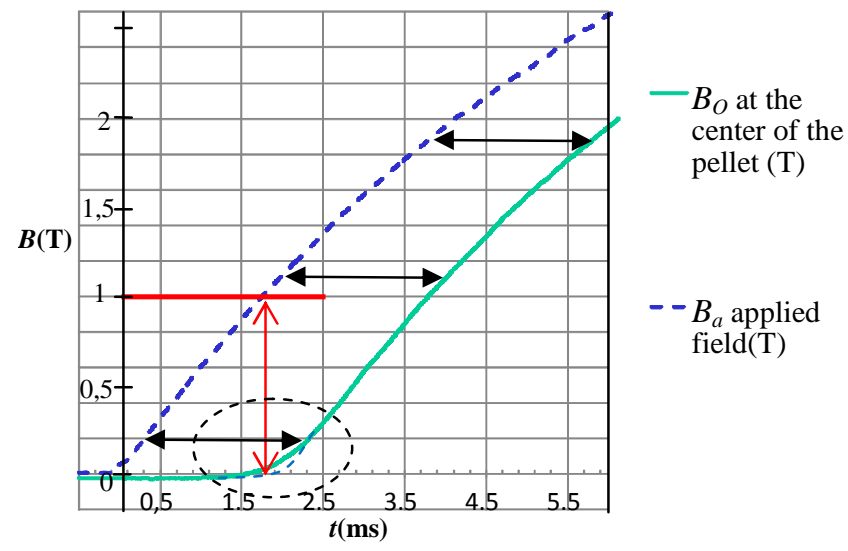

Fig. 5. Applied magnetic field and measured magnetic induction at the center of the pellet

For our two YBCuoO pellets (Fig.3), measured $B_{P}$ is $1 \mathrm{~T}$ (Fig.5). $J_{C}$ deduced from $\mathrm{B}_{\mathrm{P}}$ and (2) is $110 \mathrm{~A} / \mathrm{mm}^{2}$. It seems a realistic value of $J_{C}$ at $77 \mathrm{~K}$.

Three questions remain. What are the influence of Hall probe depth and the influence of rise rate on this $J_{C}$ determination? What about thermal effect? To answer these questions numerical simulation is necessary.

\section{Computational Method}

Pellet magnetization with axial applied magnetic is a 2D axisymetric problem. PDE interface of COMSOL 4.1 is used with or without heat transfer module. The field profiles can be computed by Faraday's law, Ampere's theorem and constitutive laws of superconducting material usually used for numerical simulation [14]-[15]:

$$
\begin{aligned}
& \nabla \times \vec{E}=-\frac{\partial \vec{B}}{\partial t} \\
& \nabla \times \vec{H}=\vec{J} \\
& E=\rho(J) . J \text { with } \rho(J)=\frac{E_{C}}{J_{C}}\left(\frac{|J|}{J_{C}}\right)^{n-1} \\
& B=\mu_{0} H
\end{aligned}
$$

To allow computing convergence a small value $\rho_{0}$, equals $1 \mathrm{e}-3 \times E_{C} / J_{C}$, is added to $\rho(J)[16]$. The common parameters 
used in these simulation are the value of $\mathrm{n}(=15$ as realistic value for HTS at $77 \mathrm{~K})$ and the dimensions of pellet $(R=1$ $\mathrm{cm}$ and $L=1 \mathrm{~cm}$ for one pellet study or $2 \times 0.5 \mathrm{~cm}$ for two pellets study). In PDE interface the applied magnetic field $B_{a}(t)$ is a condition applied at the external boundary. For thermal study convection cooling is used in heat transfer module. Thermal parameters are taken from [14].

\section{INFLUENCE OF RISE RATE, THERMAL EFFECT AND SENSOR THICKNESS.}

To answer to the three questions of section II, three sets of simulation are made.

The value of rise rate $V_{b}$ changes the distribution of magnetic field and current density due to the power law (5) instead of Bean model [17]. So the measured $B_{P}$ value must depend on rise rate. To study this phenomena (Fig. 6) simulation is made with one pellet with constant rise rate $V_{b}$ equals 1,10 and $100 \mathrm{~T} / \mathrm{s}$ and with $J_{C}=1 \mathrm{~A} / \mathrm{m}^{2}$. For this value of $J_{C}, B_{P}$ equals $9.1 \mathrm{mT}$.

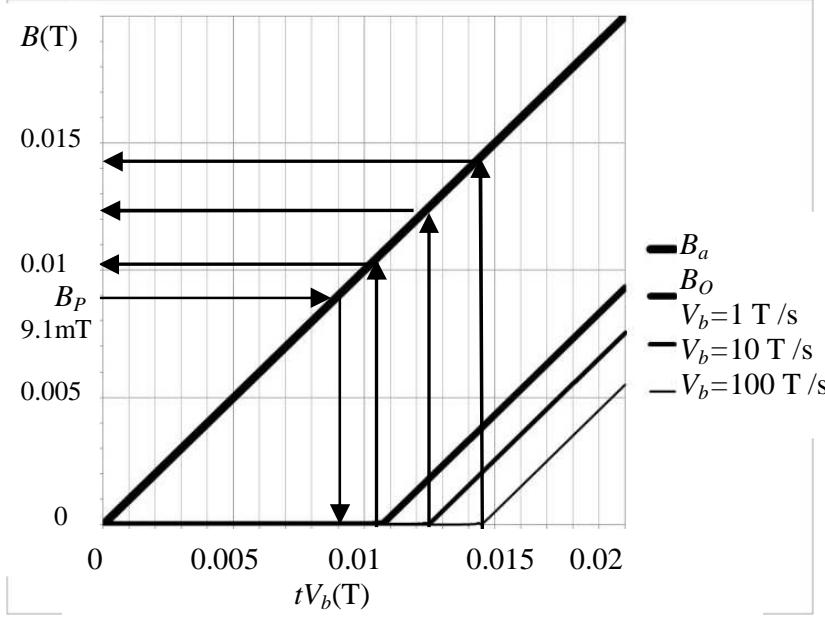

Fig. 6. Applied magnetic field and magnetic induction at the center of the pellet for different rise rates.

To allow comparison between rise rates on one figure, magnetic field in Figure 6 is represented versus $t V_{b}$. The measured $B_{P}$ increases with $V_{b}$. This is due that $J$ in superconductor is higher than $J_{C}$ until almost two times for $100 \mathrm{~T} / \mathrm{s}$ (Fig. 7). So if $\mathrm{J}$ is higher $T_{P}$ and $B_{P}$ are also higher. To correctly using (2), based on Bean model, small values of rise rate, lower than $1 \mathrm{~T} / \mathrm{s}$, are necessary. Future experiments with superconducting coil and low rise rate will be made to confirm this.

To study the influence of Hall probe thickness $e$ (Fig. 8) simulation is made with two pellets with two different thicknesses $(e=0.5$ and $1 \mathrm{~mm})$ typical of Hall probe depth and compare with one pellet without hall probe $(e=0 \mathrm{~mm})$. Figure 8 shows that measured $T_{P}$ and $B_{P}$ increase with $e$. It is due to the shape of the current density distribution near the centre of the pellets [Fig.9]. Without Hall probe (one pellet on Fig.7) the null current density area has circular shape. But due to Hall probe, this null current area becomes two areas with almost circular shape. So with Hall probe current density penetrates quicker than without probe (Fig.8). As expected the probe depth should be maximally reduce but with numerical simulation $B_{P}$ and $J_{C}$ values can be corrected.

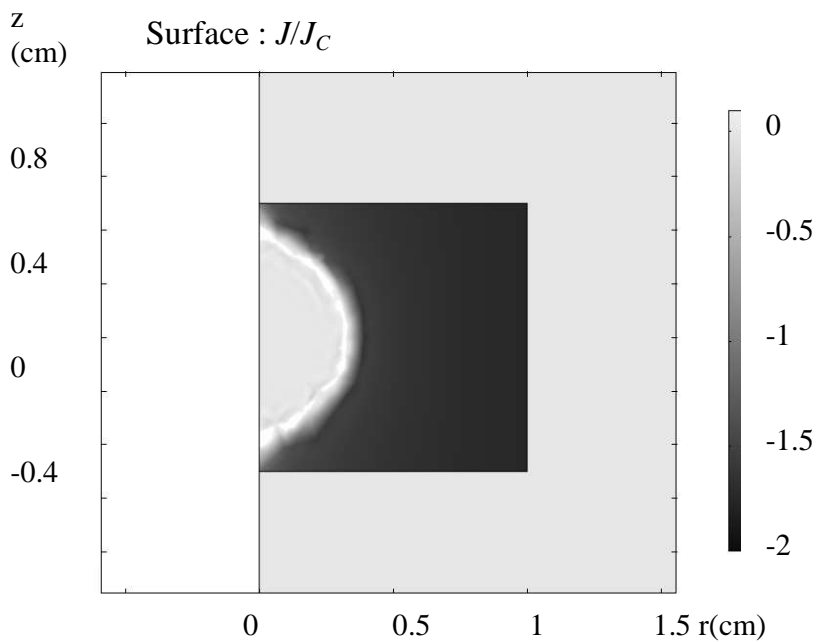

a)

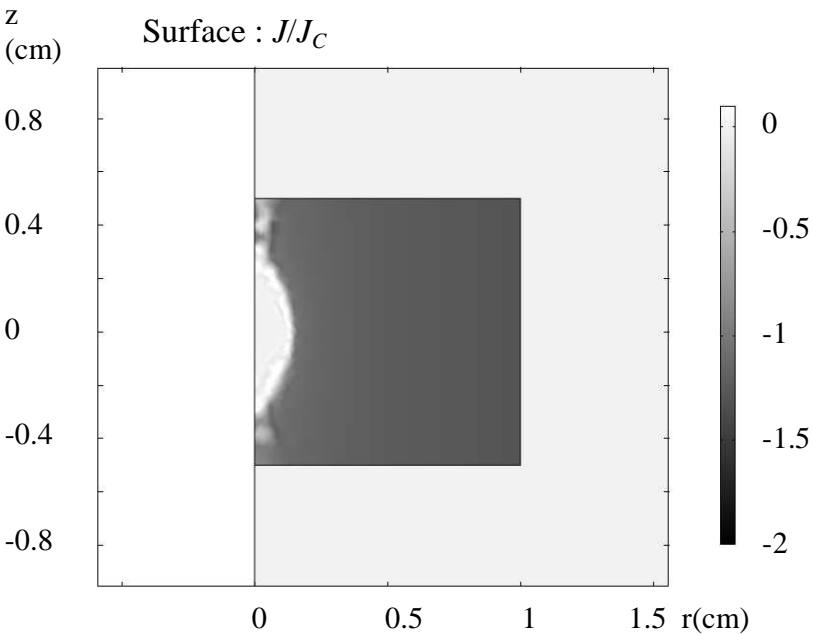

b)

Fig. 7. Current density distribution in superconducting pellet at $V b=100$ $\mathrm{T} / \mathrm{s}$ a) and $V b=1 \mathrm{~T} / \mathrm{s}$ b) for $B_{a}=B_{P}$.

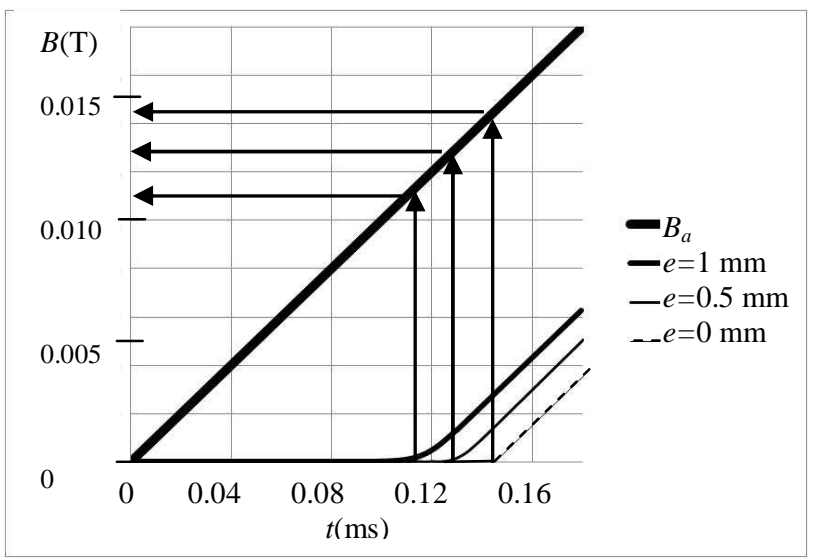

Fig. 8. Applied magnetic field and magnetic field at the center of the pellet for different Hall probe thicknesses. 
Thermal effects on $J_{C}$ determination are also numerically studied. For this $J_{C}(T)$ is taken and heater module is used in COMSOL.

$$
J_{C}(T)=J_{C}\left(\frac{T_{C}-T}{T_{C}-T_{0}}\right)
$$

$T_{0}=77 \mathrm{~K}$ is the liquid nitrogen bath constant temperature and $T_{C}=100 \mathrm{~K}[14]$.

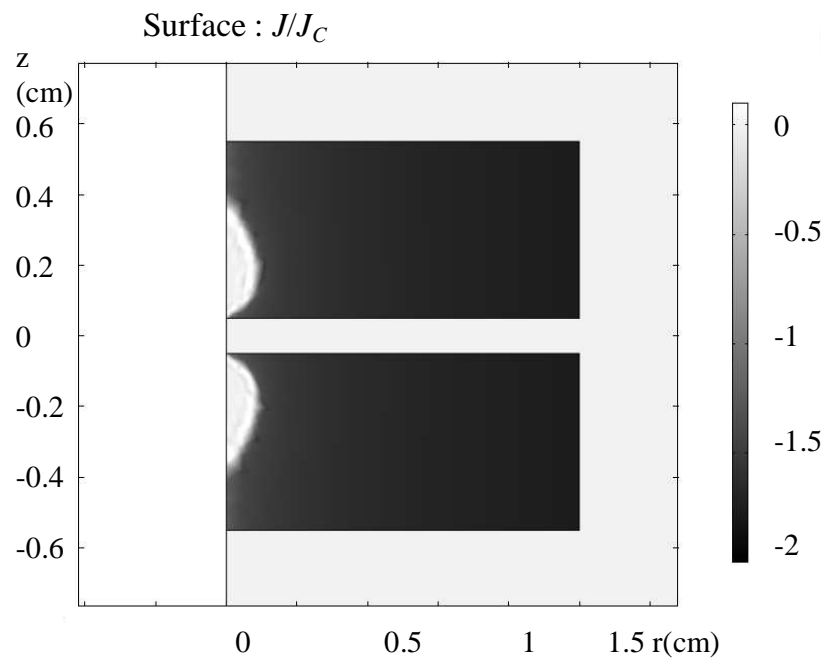

Fig. 9 Current density distribution in superconducting pellet for $e=1 \mathrm{~mm}$.

Quicker rise rate is higher thermal effects are. So the value of $V_{b}$ taken for simulation is a quick rise rate $660 \mathrm{~T} / \mathrm{s}$ and corresponds to measurement. For this value and for $J_{C}$ equals $100 \mathrm{~A} / \mathrm{mm}^{2}$, thermal effects are negligible on $B_{P}$ because temperature rising in superconductor is weak about $1^{\circ} \mathrm{K}$ or $2^{\circ} \mathrm{K}$. As a result the $J$ variation in superconductor due to thermal effects is also weak during the magnetic field penetration phase. In this $J_{C}$ determination method thermal effects can be neglected.

Finally, the best $J_{C}$ value are numerically determine to have closest numerical and experimental results of $B_{0}(t)$. For $n$-value fixed at $15, e$ fixed at $0.5 \mathrm{~mm}$, the found best $J_{C}$ equals $55 \mathrm{~A} / \mathrm{mm}^{2}$. It is about half of measured one (110 $\mathrm{A} / \mathrm{mm}^{2}$ ) mainly because rise rate is very high.

\section{CONCLUSION}

In this article a new direct $J_{C}$ determination method is presented. The experimental set up is relatively simple because it needs only one copper coil and one capacitor bank. It is a relatively precise method but it is important taking into account rise rate and sensor depth. Thermal effects can be neglected. The corrected value of $J_{C}$ is lower than measured one mainly because of high experimental rise rate. The influence of $n$-value has to be studied because it is related to the influence of rise rate. A negative point is this method does not allow to determine $J_{C}(B)$ but it is a good method to quickly obtain a first value of $J_{C}$ for bulk HTS samples.

\section{REFERENCES}

[1] A. Sanchez, C. Navau, "Critical current density from magnetization loops of finite high-TC superconductors," Superconductor Science and Technology, vol.14, pp.444-447, 2001.

[2] B. Douine, J. Leveque, S. Mezani, " $J_{C}(B)$ determination method with the help of the virgin magnetization curve of a superconducting cylinder," IEEE Trans. on Appl. Supercond., vol. 20 (2), pp.82-86, 2010.

[3] D.X. Chen, A. Sanchez, C. Navau, Y.H. Shi, D.A. Cardwell, "Critical current density of melt-grown single $\mathrm{YBaCuO}$ disks determined by ac susceptibility measurements," Superconductor science and technology, vol. ${ }^{\circ}$ 21, 085013, 6 pp., 2008.

[4] R. B. Goldfarb, M. Lelental, C.A. Thompson, "Alternating field susceptometry and magnetic susceptibility of superconductors," published in "Magnetic susceptibility of superconductors and other spin systems" Plenum Press, pp. 49-80, 1992.

[5] C. P. Bean, "Magnetization of high-field superconductors," Rev. Mod. Phys., pp.31-39, Jan. 1964.

[6] E. Durand, "Electrostatique et magnetostatique," Masson, 774 p., 1953.

[7] A. Forkl, "Magnetic flux distribution in single crystalline, ceramic and thin film high-Tc-superconductors," Physica Scripta, T49, pp. 148-158, 1993.

[8] E.H. Brandt, "Superconductor disks and cylinder in an axial magnetic field, field penetration and magnetization curves," Physical Review B, vol. 58, n¹0, pp. 6506-6522, 1998.

[9] H. T. Coffey, "Distribution of magnetic fields and currents in type II superconductors," Cryogenics, vol. 7, pp.73-77, 1967.

[10] D.J. Frankel, "Critical state model for the determination of critical currents in disk shaped superconductors," vol.50, n 8 , pp. 54025407, 1979.

[11] Bertrand Dutoit, Joseph Duron, Svetlomir Stavrev, and Francesco Grilli, "Dynamic Field Mapping for Obtaining the Current Distribution in High-Temperature Superconducting Tapes," IEEE Trans. On appl. Supercond., vol. 15, n², 2005.

[12] J. Fagnard, M. Dirickx, M. Aussloss, G. Lousberg, P. Vanderbemden, B. Vanderheyden, "Magnetic shielding properties of high-Tc superconducting hollow cylinders: model combining experimental data for axial and transverse magnetic field configurations," Superconductor science and technology, vol.22, 10, 105002, 2009.

[13] P. Laurent, J. Fagnard, N. Babu, D.A. Cardwell, B. Vanderheyden, P. Vanderbemden, "Self heating of bulk HTS of finite height subjected to a large alternating magnetic field," Superconductor science and technology, vol.23, 12, 124004, 2010.

[14] K. Berger, J. Leveque, D. Netter, B. Douine, A. Rezzoug, Influence of temperature and/or field dependence of the E-J power law on trapped magnetic field in bulk YBaCuO., IEEE Trans. on Appl. Supercond., 17(2), pp.3028-3031, june 2007.

[15] F. Sirois, F. Grilli, "Numerical considerations about using FEM to compute AC losses in HTS," IEEE Trans. On App. Supercnd., vol. $18, n^{\circ} 3,2008$.

[16] S. Stavrev, F. Grilli, B. Dutoit, N. Nibbio, E. Vinot, I. Klutch, G. Meunier, P. Tixador, Y. Yifeng, E. Martinez, "Comparison of numerical methods for modeling of superconductors." IEEE Trans. On Magn., vol. 38, n², pp.849-852, 2002.

[17] A. Kameni-Ntichi, J. Leveque, B. Douine, S. Mezani, D. Netter, "Influence of speed variation of a transverse magnetic field on a magnetization of HTS cylinder," IEEE Trans. on Appl. Supercond., vol. 21, n4, pp. 3434-3441, 2011. 